Title Page

\title{
Subclinical Hypothyroidism During Pregnancy: The Melbourne Public Hospitals Consensus
}

\section{Authors}

Peter Shane Hamblin, Department of Endocrinology \& Diabetes, Western Health, Sunshine Hospital, 176 Furlong Road, St Albans 3021 and Department of Medicine - Western Precinct, The University of Melbourne, St Albans VIC 3021

Penelope M Sheehan, Pregnancy Research Centre, Royal Women's Hospital, 20 Flemington Road, Parkville 3052 and University of Melbourne Department of Obstetrics \& Gynaecology, Royal Women’s Hospital, 20 Flemington Rd., Parkville 3052

Carolyn Allan, Endocrine Services in Pregnancy, Monash Health, 264 Clayton Road, Clayton 3168 and Hudson Institute of Medical Research, Clayton 3168

Christine A Houlihan, Mercy Hospital for Women, 163 Studley Road, Heidelberg 3084 and Austin Health, 145 Studley Road, Heidelberg 3084

Zhong X Lu, Department of Chemical Pathology, Melbourne Pathology, 103 Victoria Parade, Collingwood 3066 and Department of Medicine, Monash University, Clayton 3168

This is the author manuscript accepted for publication and has undergone full peer review but has not been through the copyediting, typesetting, pagination and proofreading process, which may lead to differences between this version and the Version of Record. Please cite this article as doi: 10.1111/imj.14210

This article is protected by copyright. All rights reserved. 
Simon P Forehan, Department of Diabetes and Endocrinology, Royal Melbourne Hospital, Parkville 3052

Duncan J Topliss, Department of Endocrinology \& Diabetes, The Alfred, Commercial Road, Melbourne 3004 and Department of Medicine, Central Clinical School, Monash University, The Alfred, Commercial Road Melbourne 3004

Christopher Gilfillan, Department of Endocrinology \& Diabetes, Eastern Health, Box Hill 3128 and Department of Medicine, Eastern Clinical School, Monash University, Box Hill 3128

Bala Krishnamurthy, Werribee Mercy Hospital, 300 Princes Highway, Werribee 3030 and St Vincents Institute of Medical Research, St Vincent’s Hospital Melbourne, Fitzroy 3065

Debra Renouf, Department of Endocrinology \& Diabetes, Peninsula Health, Frankston 3199 and Peninsula Clinical School, Monash University, Frankston 3199

Shoshana Sztal-Mazer, Department of Endocrinology \& Diabetes, The Alfred, Commercial

Road, Melbourne 3004 and Department of Medicine, Central Clinical School, Monash

University, The Alfred, Commercial Road Melbourne 3004

Suresh Varadarajan, Department of Endocrinology \& Diabetes, Northern Health, 185 Cooper Street, Epping 3076

Corresponding Author

A/Prof Peter Shane Hamblin

This article is protected by copyright. All rights reserved. 
Department of Endocrinology \& Diabetes, Western Health, Sunshine Hospital 176 Furlong Road St Albans 3021

Email: Peter.Hamblin@wh.org.au

Phone: 0383450860

\section{Acknowledgements}

No funding was received for this work. All authors disclose that they have no conflicts of interest in relation to this work.

\section{Authorship}

All authors made substantial contributions to the conception and design of the work; AND

Drafting the work or revising it critically for important intellectual content; AND

Final approval of the version to be published; AND

Agreement to be accountable for all aspects of the work in ensuring that questions related to the accuracy or integrity of any part of the work are appropriately investigated and resolved.

This article is protected by copyright. All rights reserved. 
Word count: Abstract 249 Main Text: 2792

This article is protected by copyright. All rights reserved. 


\begin{abstract}
Background

Interest in potential adverse outcomes associated with maternal subclinical hypothyroidism (normal Free T4, elevated TSH) has increased significantly over recent years. In turn, the frequency of maternal thyroid function testing has risen, despite universal thyroid function screening not being recommended, leading to a marked increase in referrals to obstetric endocrinology clinics. In 2017 the American Thyroid Association (ATA) revised their diagnostic and management guidelines. While welcome, these new guidelines contain recommendations which may cause confusion in clinical practice.
\end{abstract}

\title{
Aims
}

To ensure uniform practice in the diagnosis and management of subclinical hypothyroidism in pregnancy across all Melbourne Public Hospitals.

\section{Results}

Consensus was achieved and the guidelines were endorsed by the Council of the Endocrine Society of Australia. Trimester and assay specific TSH reference intervals derived from healthy local populations should be used, where available. When unavailable, a TSH cut-off of $4 \mathrm{mU} / \mathrm{L}$ (replacing the previously recommended $2.5 \mathrm{mU} / \mathrm{L}$ ) should be used to initiate treatment, irrespective of thyroid autoantibody status. The recommended starting dose of levothyroxine is 
50 ug daily, with a therapeutic TSH target of $0.1 \mathrm{mU} / \mathrm{L}$ to $2.5 \mathrm{mU} / \mathrm{L}$. Levothyroxine should generally be ceased after delivery, with some exceptions. Hospitals will ensure smooth transfer of care back to the woman's general practitioner with clear documentation of pregnancy thyroid management and a recommended plan for follow-up.

\section{Conclusions}

Fewer women will be classified as having subclinical hypothyroidism during pregnancy, which is likely to lead to reductions in emotional stress, hospital visits, repeated blood tests and financial costs. Uniform clinical practice will occur across Melbourne.

\section{Key Words}

Subclinical hypothyroidism; Hypothyroidism; Pregnancy

This article is protected by copyright. All rights reserved. 


\section{Introduction}

Although universal maternal thyroid function testing is not recommended by Australian guidelines, an increasing number of women are nonetheless having thyroid screening in early pregnancy. This has led to a marked increase in referrals to obstetric endocrinology clinics.

Severe hypothyroidism is associated with detrimental fetal effects, most notably cretinism due to iodine deficiency (1). Consistent with this, Haddow et al reported an association between maternal hypothyroidism and reduction in IQ in the offspring (2). This retrospective cohort study included cases of "overt” hypothyroidism (low Free T4, high TSH) and subclinical hypothyroidism (normal Free T4, high TSH). A subsequent observational study demonstrated an inverse correlation between severity of maternal hypothyroidism and IQ of eight year old offspring (3).

\section{Subclinical hypothyroidism in pregnancy}

The possibility that maternal subclinical hypothyroidism may also cause long term adverse effects on fetal brain development is contentious. Data suggestive of possible fetal harm are all observational. A recent prospective cohort study found mild thyroid dysfunction in early pregnancy did not adversely affect educational attainment (4), but other observational studies have shown conflicting results. A meta-analysis of 11 observational studies found evidence of an effect of maternal subclinical hypothyroidism on the risk of intellectual impairment in

This article is protected by copyright. All rights reserved. 
children, but when only the studies reporting odds ratios directly (six studies) were included in the meta-analysis, this association was no longer significant (5). Interventional randomised controlled trials of levothyroxine during pregnancy have shown no benefit compared to placebo treatment ( 6-8). These studies have been criticised on the grounds that treatment may have been started too late in the pregnancy to show a benefit, given critical aspects of fetal brain development occur between 11 and 14 weeks' gestation (9).

A link between subclinical hypothyroidism and adverse pregnancy outcomes is also unclear, with variable associations demonstrated in observational studies (10). In one secondary analysis, reduction in the risk of a composite pregnancy outcome (including miscarriage and preterm delivery) was reported when treatment was begun by the end of the first trimester in antithyroid peroxidase antibody (anti-TPO) positive women (11). A further study of anti-TPO positive women with TSH $>2.5 \mathrm{mU} / \mathrm{L}$ treated with levothyroxine before 14 weeks gestation also found a reduced risk of pre-term delivery, but mainly in those with TSH $>4.0 \mathrm{mU} / \mathrm{L}$ (12). A subsequent study from the same group failed to show any levothyroxine treatment difference in pre-term delivery in anti-TPO negative women when a TSH cut-off of $2.5 \mathrm{mU} / \mathrm{L}$ was applied, but there was a reduction using a TSH cut-off of $4.0 \mathrm{mU} / \mathrm{L}$ (13). A retrospective analysis of a large US administrative claims database showed that pregnant women with subclinical hypothyroidism treated with levothyroxine had reduced pregnancy loss compared to untreated women, but only in those with pre-treatment TSH concentration of 4.1-10 mU/L (14). 
Limitations of this study included the retrospective observational design, potential for misclassification, selection bias and other confounders.

A recent systematic review involving 3,995 pregnant women supported an association between subclinical hypothyroidism and adverse maternal and neonatal outcomes, however, this association may not be causal and may be overestimated by publication bias (15).

Even in overt hypothyroidism (unless due to severe iodine deficiency) it is unclear whether the association with adverse maternal outcomes and neonatal outcomes of preterm birth, low birth weight and neonatal death is causal. An increased incidence of pregnancy complications has often been described in overt hypothyroidism including preterm birth, low birth weight, perinatal death, pregnancy induced hypertension, pre-eclampsia, placental abruption, anaemia and postpartum haemorrhage. A close examination of the studies reveals that for many of these the association could be due to confounding factors (e.g. maternal age, obesity).

One study took the unusual approach of blinding clinicians to thyroid function results (16). Of the 586 pregnant women, 14 had overt hypothyroidism, 66 had subclinical hypothyroidism, two had subclinical hyperthyroidism and seven had overt hyperthyroidism. No significant differences in gestational age at delivery between the groups were found and after adjustment for 
maternal age and BMI there were no significant associations with the outcomes of pre-eclampsia, fetal growth restriction, preterm delivery or Apgar score.

One of the larger studies of pregnancy outcomes in thyroid disease (17) included retrospective data for 223,512 singleton pregnancies. The women with thyroid disease were older, more often multiparous, and had more chronic conditions than women without thyroid disease. In addition, women with primary hypothyroidism and unspecified thyroid disease were more likely to be overweight or obese. All these represent significant confounding factors for the most commonly quoted associations.

An outcome such as preterm birth is highly confounded in the literature by not being separated into spontaneous and indicated preterm births. A recent meta-analysis identified only one study in which preterm births were clearly identified as spontaneous (18). When women with comorbidities were excluded, the association with premature birth disappeared. Even well conducted prospective studies with recorded thyroid function results are usually underpowered to examine relatively rare outcomes such as pre-eclampsia.

\section{Subclinical hypothyroidism and spontaneous abortion}

This article is protected by copyright. All rights reserved. 
One of the most accepted associations is between thyroid disease and miscarriage, however even here the study findings are contentious. A recent study of infertile women as part of two large randomised controlled trials showed no association between TSH $\geq 2.5 \mathrm{mU} / \mathrm{L}$ and miscarriage (19). This result does not preclude an association, but it does show the well-known TSH cut-off of $2.5 \mathrm{mU} / \mathrm{L}$ is not a discriminator for this outcome. The authors did find a significant association with miscarriage and the presence of anti-thyroid antibodies in direct contrast to the outcome of a recent meta-analysis which concluded that there was no association (20). Other recent studies regarding the role of anti-thyroid antibodies and miscarriage have also had conflicting results $(21,22)$. Currently there is no clear evidence that anti-thyroid antibody positive women with TSH below $4 \mathrm{mU} / \mathrm{L}$ are at increased risk of miscarriage. Additionally the majority of studies have been in women with infertility, raising concerns that the findings may not be applicable to the general population.

The possible role of thyroid auto-immunity in the presence of normal thyroid function is beyond the scope of this paper.

\section{Thyroid function testing in pregnancy}

When making treatment decisions based on TSH in pregnancy, important factors which should be considered are often overlooked. This is of particular importance given that a borderline 
increase in TSH may well determine a recommendation for treatment with levothyroxine for the rest of the pregnancy.

Factors including ethnicity, weight and even time of day of the blood sample may all influence TSH. The situation is further complicated by the physiological thyroid function changes that occur during normal pregnancy. Dynamic changes in thyroid function are mainly caused by changes in human chorionic gonadotropin (hCG) levels which peak at around 10 weeks gestation then decrease. HCG has weak TSH-like activity which can stimulate the TSH receptor to increase thyroid hormone production $(23,24)$. The consequent downward shift in TSH is mostly seen at 7 to 12 weeks gestation $(25,26)$ and typically does not occur prior to 7 weeks gestation (27).

Additionally significant variations in TSH assays exist which can result in marked differences in the prevalence of subclinical hypothyroidism. Currently, four common commercial TSH methods are used in Australia, manufactured by Roche, Abbott, Siemens, and Beckman. A correlation study using sera collected during 9-13 weeks gestation from women in a prospective study of longitudinal assessment of thyroid function in pregnancy (28) showed significant method differences for TSH results with the Abbott method yielding the lowest TSH, Roche the highest and the other two methods in between for the same standard TSH sample. (29). 


\title{
American Thyroid Association 2017 Guidelines
}

The American Thyroid Association (ATA) has become the de facto international organisation whose treatment guidelines for thyroid disease are accepted worldwide. The ATA first published guidelines relating to pregnancy and thyroid disorders in 2011. The field has seen rapid growth in the published literature and hence extensively revised 2017 guidelines were developed (30). The 2017 ATA guidelines include 97 recommendations and provide a framework for management, while recognising the many areas of uncertainty.

\begin{abstract}
Although it has consistently been recommended that pregnancy-specific population based reference intervals should be determined locally, this has seldom been achieved in clinical practice. Consequently, there has been widespread adoption of prescriptive cut-off values recommended in the 2011 ATA guidelines with TSH upper limits of $2.5 \mathrm{mU} / \mathrm{L}$ and $3.0 \mathrm{mU} / \mathrm{L}$ for the first and second/third trimesters, respectively, to initiate levothyroxine treatment in pregnancy. It should be noted that some experts have recommended against prescriptive upper TSH limits which may have been set too low and it is argued are likely to cause more harm than benefit (31).
\end{abstract}

The 2017 ATA guidelines again emphasise that population and trimester specific reference intervals for serum TSH during pregnancy should be used, ideally defined in healthy thyroid antibody negative pregnant women with optimal iodine intake and without thyroid illness. When

This article is protected by copyright. All rights reserved. 
this is not feasible, extrapolation of pregnancy-specific TSH reference intervals from similar patient populations and performed using similar TSH assays is recommended.

Importantly, revision of the prescriptive upper reference limit for TSH from $2.5 \mathrm{mU} / \mathrm{L}$ to 4.0 $\mathrm{mU} / \mathrm{L}$ is recommended if internal or transferable pregnancy-specific TSH reference intervals are not available (30). This recommendation may substantially reduce the number of women diagnosed with subclinical hypothyroidism.

\section{Potential areas of confusion using the 2017 ATA Guidelines}

Whilst the long awaited 2017 ATA guideline revision was clearly welcome, a number of the recommendations are based on low quality evidence. Additionally, the guidelines lack clarity regarding the key clinical question: when to start levothyroxine, which is a time sensitive decision. Instead, a treatment algorithm is provided based on the presence or absence of antiTPO antibodies, a result not often available when the initial elevated TSH is discovered. Furthermore, thyroid autoantibody levels decline as gestation advances ( 32, 33), with up to 50\% of women losing anti-TPO antibody positivity in the second and third trimesters ( 33 ). The guidelines refer to this phenomenon, but do not provide guidance on how to deal with the implications.

This article is protected by copyright. All rights reserved. 
The guidelines state that if a woman is anti-TPO antibody positive, treatment with levothyroxine is recommended if the TSH level is above the upper limit of the trimester-specific TSH reference interval. Yet levothyroxine treatment may also be used if anti-TPO antibody levels are elevated and TSH is between $2.5 \mathrm{mU} / \mathrm{L}$ and the trimester-specific upper limit. In a major departure from previous practice, when anti-TPO antibodies are negative, levothyroxine treatment is not recommended until TSH is above $10 \mathrm{mU} / \mathrm{L}$.

As a result, the 2017 ATA guidelines allow clinicians to choose from several options regarding the accepted upper limit of a normal TSH in pregnancy and the cut-off TSH before initiation of levothyroxine therapy. Decision making becomes complex! Furthermore, given that anti-TPO antibody status is not routinely tested when TSH is performed, a subsequent blood test for antiTPO antibodies will be required for many pregnant women with TSH in the equivocal range, leading to increased pathology and consultation costs, as well as a potential delay in treatment.

We acknowledge that no one approach is clearly superior. However, in busy public hospital obstetric clinics, leaving the choice to individual clinicians can cause confusion and miscommunication. A woman may potentially receive conflicting advice from one clinic appointment to the next depending on the individual endocrinologist or obstetrician. Different

This article is protected by copyright. All rights reserved. 
hospitals in the same city may choose different TSH cutoffs to define subclinical hypothyroidism and levothyroxine treatment may be recommended by one hospital but not the other. In the age of social media, consistency of management approach across sites is crucial to patient confidence in our health care delivery system.

In order to avoid these predictable problems, endocrinologists and obstetricians involved in the care of pregnant women in all Melbourne public obstetric hospitals resolved to develop an agreed position regarding the diagnosis and management of subclinical hypothyroidism in pregnancy. These hospitals are responsible for more than 40,000 births annually (34).

\section{Methods}

The 2017 ATA guidelines and other relevant literature were reviewed by representatives from all Melbourne public hospital networks providing obstetric services (Alfred Health, Eastern Health, Mercy Hospital for Women, Monash Health, Northern Health, Peninsula Health, Royal Women’s Hospital, Werribee Mercy and Western Health).

A meeting was then convened in Melbourne in May 2017 and held during the Endocrine Society of Australia Annual Seminar meeting. At that meeting all Melbourne public hospitals were

This article is protected by copyright. All rights reserved. 
represented as well as endocrinologists from regional Victoria, other Australian states and New Zealand.

Consensus guidelines regarding the diagnosis and management of subclinical hypothyroidism in pregnancy were developed and subsequently the guidelines were refined by email discussion. Each recommendation was classified according to The National Health and Medical Research Council criteria ( 35$)$.

The consensus guidelines were then referred to the Endocrine Society of Australia for consideration and subsequently were endorsed by the Council of the Endocrine Society of Australia in August 2018.

\section{Results}

In line with the 2017 ATA guidelines, universal thyroid function testing in pregnancy was not recommended. Selective screening of women at higher risk of thyroid disease (e.g. history of past thyroid disease, age $>30$, obesity (BMI $>40 \mathrm{~kg} / \mathrm{m}^{2}$ ), personal or family history of autoimmune disease, presence of goitre, use of medications that can affect thyroid function and past history of infertility, pregnancy loss or neck irradiation) as specified in the ATA 2017

This article is protected by copyright. All rights reserved. 
guidelines was endorsed (30). The management of isolated maternal hypothyroxinaemia (low FT4 with normal TSH) is controversial. The ATA recommendation to not routinely treat during pregnancy was endorsed (30).

The evidence in the literature relating to subclinical hypothyroidism in pregnancy was considered to be generally of only modest quality and the strength of each consensus guideline recommendation was graded only moderate or weak. The consensus is summarised in Table 1 .

The major change is the TSH level at which treatment with levothyroxine is recommended. Where trimester-specific TSH reference intervals are not available, a TSH concentration above 4 $\mathrm{mU} / \mathrm{L}$ is the new agreed level for initiation of levothyroxine therapy. This is to replace the previously recommended TSH upper limits of $2.5 \mathrm{mU} / \mathrm{L}$ and $3.0 \mathrm{mU} / \mathrm{L}$ for the first and second and third trimesters respectively. In cases of borderline elevation of TSH, it is recommended to repeat the test without delay, in the same laboratory, to ensure that TSH is indeed elevated before committing the mother to levothyroxine therapy for the remainder of the pregnancy. If a local trimester and population-specific TSH reference interval is available, the cut-off to start levothyroxine is a TSH above the upper limit of that reference interval. This consensus recommendation is made irrespective of maternal anti-TPO antibody status, firstly to avoid unnecessary complexity and secondly in recognition of the conflicting evidence in relation to the impact of thyroid auto-immunity per se on pregnancy outcomes.

This article is protected by copyright. All rights reserved. 
Other recommendations include the proposal that anti-TPO antibodies should be measured in women where the TSH is above $4 \mathrm{mU} / \mathrm{L}$ (or above the trimester and population-specific reference interval). This is to assist decision making at the end of the pregnancy when deciding whether to stop levothyroxine, rather than to determine who should receive levothyroxine during pregnancy. Although the majority of women have a return to normal thyroid function after pregnancy, where anti-TPO antibodies are strongly positive (three times the normal upper limit or higher), treatment should generally continue postpartum because of the higher risk of ongoing hypothyroidism. In a study of women with subclinical hypothyroidism in pregnancy, where antibody measurements were available, women with positive thyroid peroxidase antibodies in pregnancy were more likely to have persistently elevated TSH, or be receiving levothyroxine replacement 5 years after pregnancy compared to antibody negative women (6 of 7 [86\%] vs 10 of 57 [18\%], $\mathrm{P}<.001)(36)$.

The remaining recommendations relate to practical management aspects. The starting dose of 50 microgram levothyroxine daily and the frequency of re-checking thyroid function while on treatment are in keeping with common clinical practice ( 37).

This article is protected by copyright. All rights reserved. 
The recommendation regarding the levothyroxine-treated TSH target $(0.1 \mathrm{mU} / \mathrm{L}$ to $2.5 \mathrm{mU} / \mathrm{L})$ was the subject of considerable debate at the May 2017 meeting, as it is evidently inconsistent with the cut-off TSH of $4 \mathrm{mU} / \mathrm{L}$ to initiate levothyroxine treatment. It was, however, decided to remain consistent with the ATA guidelines which recommend this target range, while acknowledging that the evidence underpinning this recommendation is of low quality.

The remainder of the recommendations are designed to provide a uniform approach regarding whether to stop levothyroxine at the end of pregnancy and to guide postpartum thyroid function testing, again recognising the low quality evidence for these recommendations. The final recommendation was designed to ensure safe handover of care to the woman's general practitioner.

\section{Conclusion}

As more evidence accrues it will be appropriate to revise these Melbourne Consensus Guidelines. For now they achieve the important goal of providing uniform clinical practice across Melbourne, which should reduce confusion, expense and unnecessary stress on both mothers and clinicians.

This article is protected by copyright. All rights reserved. 


\section{References}

1. Hetzel BS. The challenge of public health in Australia and the region. Med $J$ Aust 2006;185(11): 646-650.

2. Haddow JE, Palomaki GE, Allan WC, Williams JR, Knight GJ, Gagnon J et al. Maternal thyroid deficiency during pregnancy and subsequent neuropsychological development of the child. N Engl J Med 1999;341(8): 549-555.

3. Klein RZ, Sargent JD, Larsen PR, Waisbren SE, Haddow JE, Mitchell ML. Relation of severity of maternal hypothyroidism to cognitive development of offspring. J Med Screen 2001;8: 18-20.

4. Nelson SM, Haig C, McConnachie A, Sattar N, Ring SM, Smith GD et al. Maternal thyroid function and child educational attainment: prospective cohort study. BMJ 2018 360: k452 doi.org./10.1136/bmj.k452

5. Thompson W, Russell G, Baragwanath G, Matthews J, Vaidya B, Thompson-Coon J. Maternal thyroid hormone insufficiency during pregnancy and risk of neurodevelopmental disorders in offspring: A systematic review and meta- analysis Clinical Endocrinology 2018; 88:575-584.

This article is protected by copyright. All rights reserved. 
6. Yamamoto JM, Benham JL, Nerenberg KA, Donovan LE. Impact of levothyroxine therapy on obstetric, neonatal and childhood outcomes in women with subclinical hypothyroidism diagnosed in pregnancy: a systematic review and meta-analysis of randomised controlled trials. BMJ Open 2018;8:e22837. doi:10.1136/ bmjopen-2018-022837

7 Lazarus JH, Bestwick JP, Channon S, Paradice R, Maina A, Rees R et al. Antenatal thyroid screening and childhood cognitive function. N Engl J Med 2012;366(6): 493-501.

8 Casey BM, Thom EA, Peaceman AM, Varner MW, Sorokin Y, Hirtz DG et al. Treatment of subclinical hypothyroidism or hypothyroxinemia in pregnancy. N Engl J Med 2017; 376(9): 815-25.

9 Obregon MJ, Escobar del Rey F. Role of thyroid hormone during early brain development. Eur J Endocrinol 2004;151 (Suppl 3): U25-U37.

10 Krassas GE, Poppe K, Glinoer D. Thyroid function and human reproductive health. Endocr Rev 2010;31(5): 702-755.

This article is protected by copyright. All rights reserved. 
11 Negro R, Schwartz A, Gismondi R, Tinelli A, Mangieri T, Stagnaro-Green A. Universal screening versus case finding for detection and treatment of thyroid hormonal dysfunction during pregnancy. J Clin Endocrinol Metab 2010;95(4): 1699-1707.

12 Nazarpour S, Tehrani FR, Simbar M, Tohidi M, Alavi Majd H, Azizi F. Effects of levothyroxine treatment on pregnancy outcomes in pregnant women with autoimmune thyroid disease. Eur J Endocrinol 2017;176: 253-265.

13 Nazarpour S, Tehrani FR, Simbar M, Tohidi M, Minooee S Rahmati M et al. Effects of levothyroxine on pregnant women with subclinical hypothyroidism, negative for thyroid peroxidase antibodies. J Clin Endocrinol Metab 2018;103(3): 926-935.

14 Maraka S, Mwangi R, McCoy R, Yao X, Sangaralingham LR, Singh Ospina NM et al. Thyroid hormone treatment among pregnant women with subclinical hypothyroidism: US national assessment. BMJ 2017;356: i6865. doi:10.1136/bmj.i6865.

15 Maraka S, Ospina NMS, O’Keeffe DT, Espinosa De Ycaza AE, Gionfriddo MR, Erwin PJ et al. Subclinical hypothyroidism in pregnancy: a systematic review and metaanalysis. Thyroid 2016;26(4): 580-590.

This article is protected by copyright. All rights reserved. 
16 Saki F, Dabbaghmanesh MH, Ghaemi SZ, Forouhari S, Ranjbar Omrani G, Bakhshayeshkaram M. Thyroid function in pregnancy and its influences on maternal and fetal outcomes. Int J of Endocrinol Metab 2014;12(4): e19378. doi:10.5812/ijem.19378.

17 Männistö T, Mendola P, Grewal J, Xie Y, Chen Z, Laughon SK. Thyroid diseases and adverse pregnancy outcomes in a contemporary US cohort. J Clin Endocrinol Metab 2013;98(7): 2725-2733.

18 Sheehan PM, Nankervis A, Araujo Júnior E, Da Silva Costa F. Maternal thyroid disease and preterm birth: systematic review and meta-analysis. J Clin Endocrinol Metab 2015;100(11): 4325-4331.

19 Seungdamrong A, Steiner AZ, Gracia CR, Legro RS, Diamond MP, Coutifaris C et al. Preconceptional antithyroid peroxidase antibodies, but not thyroid-stimulating hormone, are associated with decreased live birth rates in infertile women. Fertil Steril 2017;108(5): 843850.

This article is protected by copyright. All rights reserved. 
20 Leiva P, Schwarze JE, Vasquez P, Ortega C, Villa S, Crosby J et al. There is no association between the presence of anti-thyroid antibodies and increased reproductive loss in pregnant women after ART: a systematic review and meta-analysis. JBRA Assist Reprod 2017; 21(4): 361-365.

21 Plowden TC, Schisterman EF, Sjaarda LA, Zarek SM, Perkins NJ, Silver R et al, Subclinical hypothyroidism and thyroid autoimmunity are not associated with fecundity, pregnancy loss, or live birth. J Clin Endocrinol Metab 2016;101(6): 2358-65.

22 He H, Jing S, Gong F, Tan YQ, Lu GX, Lin G. Effect of thyroid autoimmunity per se on assisted reproduction treatment outcomes: A meta-analysis. Taiwan J Obstet Gynecol. 2016;55(2): 159-65.

23 Glinoer D, De Nayer P, Bourdoux P, Lemone M, Robyn C, van Steirteghem A et al. Regulation of maternal thyroid during pregnancy. $\quad J$ Clin Endocrinol Metab 1990;71(2): 276-287.

24 Glinoer D. The regulation of thyroid function in pregnancy: pathways of endocrine adaptation from physiology to pathology. Endocr Rev 1997;18: 404-433.

This article is protected by copyright. All rights reserved. 
25 Gilbert RM, Hadlow NC, Walsh JP, Fletcher SJ, Brown SJ, Stuckey BG et al. Assessment of thyroid function during pregnancy: first-trimester (weeks 9-13) reference intervals derived from Western Australian women. Med J Aust 2008;189 (5): 250-253.

26 Laurberg P, Andersenet SL, Hindersson P, Nohr EA, Olsen J. Dynamics and predictors of serum TSH and fT4 reference limits in early pregnancy: a study with the Danish national birth cohort. J Clin Endocrinol Metab 2016;101(6): 2484-2492.

27 Li C, Shan Z, Mao J, Wang W, Xie X, Zhou W et al. Assessment of thyroid function during first-trimester pregnancy: what is the rational upper limit of serum TSH during the first trimester in Chinese pregnant women? J Clin Endocrinol Metab 2014;99(1): 73-79.

28 Ekinci EI, Lu ZX, Sikaris K, Bittar I, Cheong KY, Lam Q et al. Longitudinal assessment of thyroid function in pregnancy. Ann Clin Biochem 2013;50: 595-602.

29 Lu ZX, Ekinci EI, Chiu WL, et al. Can we harmonise gestational age-specific limits for TSH? (Abstract) Proceedings of the Australasian Association of Clinical Biochemists’52nd Annual Scientific Conference. Clin Biochem Rev 2014;35(Supp): S35.

This article is protected by copyright. All rights reserved. 
30 Alexander EK, Pearce EN, Brent GA, Brown RS, Chen H, Dosiou C et al. 2017 Guidelines of the American Thyroid Association for the diagnosis and management of thyroid disease during pregnancy and the postpartum. Thyroid 2017;27(3): 315-389.

31 Korevaar TIM. The upper limit for TSH during pregnancy: why we should stop using fixed limits of 2.5 or 3.0 mU/l. Thyroid Research 2018 11:5 https://doi.org/10.1186/s13044-0180048-7

32 Glinoer D, Riahi M, Grün JP, Kinthaert J. Risk of subclinical hypothyroidism in pregnant women with asymptomatic autoimmune thyroid disorders. J Clin Endocrinol Metab 1994;79 (1): 197-204.

33 Ekinci EI, Chiu WL, Lu ZX, Sikaris K, Churilov L, Bittar I et al. A longitudinal study of thyroid autoantibodies in pregnancy: the importance of test timing. Clin Endocrinol 2015;82: 604-610.

34 The Consultative Council on Obstetric and Paediatric Mortality and Morbidity: Victoria’s mothers, babies and children 2014 and 2015, Available at https://www2.health.vic.gov.au/hospitals-and-health-services/quality-safety-

This article is protected by copyright. All rights reserved. 
service/consultative-councils/council-obstetric-paediatric-mortality/ accessed 13 September 2018.

35 NHMRC additional levels of evidence and grades for recommendations for developers of guidelines, Available at https://www.nhmrc.gov.au/_files_nhmrc/file/guidelines/developers/nhmrc_levels_grades _evidence_120423.pdf accessed 13 September 2018

36 Shields BM, Knight BA, Hill AV, Hattersley AT, Vaidya B. Five-Year Follow-Up for Women With Subclinical Hypothyroidism in Pregnancy, J Clin Endocrinol Metab, 98 (12), 2013 E1941-E1945.

37 Hypothyroidism [revised 2013 Nov]. In: eTG complete [Internet]. Melbourne: Therapeutic Guidelines Limited. 2017 Nov, accessed 13 September 2018

This article is protected by copyright. All rights reserved. 
Table 1. Consensus Guidelines for the Management of Subclinical Hypothyroidism During Pregnancy in all Melbourne Public Hospitals*

1. Irrespective of thyroid antibody status, levothyroxine therapy is started in pregnant women if TSH is $>4$ $\mathrm{mU} / \mathrm{L}$ (confirmed by a repeat test done in the same laboratory without delay in cases where TSH is only borderline elevated)

Where population-specific and gestation-specific TSH reference intervals are available, TSH results above the upper limit of these reference intervals are to be used instead of TSH $>4 \mathrm{mU} / \mathrm{L}$

NHMRC Level of evidence: III-2

GRADE B

2. Anti-Thyroid Peroxidase (Anti-TPO) antibody status is checked in all pregnant women with TSH $>4 \mathrm{mU} / \mathrm{L}$

NHMRC Level of evidence: III-2

GRADE B

3. Isolated hypothyroxinaemia (Low Free T4, normal TSH) in pregnancy is not routinely treated

NHMRC Level of evidence: III-2

GRADE B

4. Levothyroxine starting dose is generally $\mathbf{5 0}$ ug daily

NHMRC Level of evidence: IV

GRADE C

5. Target TSH when on treatment with levothyroxine is: $0.1 \mathrm{mU} / \mathrm{L}$ to $2.5 \mathrm{mU} / \mathrm{L}$

NHMRC Level of evidence: III-3

GRADE C

6. Free T4 and TSH should be re-checked six weeks after initiation of levothyroxine, and six weekly thereafter throughout the pregnancy to guide levothyroxine dose adjustment

If TSH is in the target range at $\mathbf{3 0}$ weeks gestation, further thyroid function tests are not required for the rest of the pregnancy 
NHMRC Level of evidence: III-3

GRADE C

6. Levothyroxine is ceased after delivery in all women except those:

- contemplating a repeat pregnancy within 12 months of giving birth

- attempting to conceive again with a history of unexplained spontaneous abortion

- who had TSH > $10 \mathrm{mU} / \mathrm{L}$ prior to commencing levothyroxine therapy

- with strongly positive anti-TPO antibodies (i.e. more than three times upper limit of normal)

NHMRC Level of evidence: III-3

GRADE D

7. In cases where levothyroxine is continued, individualised follow-up arrangements should be made

Unless initial TSH was $>10 \mathrm{mU} / \mathrm{L}$, levothyroxine cessation should be considered on an annual basis, as long term therapy may not be required.

NHMRC Level of evidence: III-3

GRADE C

8. All women should be advised to have a re-check of Free T4 and TSH six weeks post partum. Women will generally be asked to see their local doctor to discuss the results

NHMRC Level of evidence: III-3

GRADE C

9. A letter should be sent to the local doctor (with a copy to the patient) communicating the fact that levothyroxine had been used during pregnancy and the need to re-check Free T4 and TSH at 6 weeks postpartum

The letter should also provide a phone number for the local doctor to contact an experienced clinician at the hospital regarding any queries relating to the postpartum thyroid function results

NHMRC Level of evidence: Not applicable

GRADE Not applicable 
*These Guidelines may be varied at the discretion of an experienced clinician.

NHMRC: National Health and Medical Research Council 
Table 1. Consensus Guidelines for the Management of Subclinical Hypothyroidism During Pregnancy in all Melbourne Public Hospitals*

1. Irrespective of thyroid antibody status, levothyroxine therapy is started in pregnant women if TSH is $>4$ $\mathrm{mU} / \mathrm{L}$ (confirmed by a repeat test done in the same laboratory without delay in cases where TSH is only borderline elevated)

Where population-specific and gestation-specific TSH reference intervals are available, TSH results above the upper limit of these reference intervals are to be used instead of TSH $>4 \mathrm{mU} / \mathrm{L}$

NHMRC Level of evidence: III-2

GRADE B

2. Anti-Thyroid Peroxidase (Anti-TPO) antibody status is checked in all pregnant women with TSH $>4 \mathrm{mU} / \mathrm{L}$

NHMRC Level of evidence: III-2

GRADE B

3. Isolated hypothyroxinaemia (Low Free T4, normal TSH) in pregnancy is not routinely treated

NHMRC Level of evidence: III-2

GRADE B

4. Levothyroxine starting dose is generally 50 ug daily

NHMRC Level of evidence: IV

GRADE C

5. Target TSH when on treatment with levothyroxine is: $0.1 \mathrm{mU} / \mathrm{L}$ to $2.5 \mathrm{mU} / \mathrm{L}$

NHMRC Level of evidence: III-3

GRADE C

6. Free $\mathrm{T} 4$ and TSH should be re-checked six weeks after initiation of levothyroxine, and six weekly thereafter throughout the pregnancy to guide levothyroxine dose adjustment

If TSH is in the target range at $\mathbf{3 0}$ weeks gestation, further thyroid function tests are not required for the rest of the pregnancy

NHMRC Level of evidence: III-3

GRADE C

6. Levothyroxine is ceased after delivery in all women except those:

- contemplating a repeat pregnancy within 12 months of giving birth

- attempting to conceive again with a history of unexplained spontaneous abortion 
- who had TSH $>10 \mathrm{mU} / \mathrm{L}$ prior to commencing levothyroxine therapy

- with strongly positive anti-TPO antibodies (i.e. more than three times upper limit of normal)

NHMRC Level of evidence: III-3

GRADE D

7. In cases where levothyroxine is continued, individualised follow-up arrangements should be made

Unless initial TSH was $>10 \mathrm{mU} / \mathrm{L}$, levothyroxine cessation should be considered on an annual basis, as long term therapy may not be required.

NHMRC Level of evidence: III-3

GRADE C

8. All women should be advised to have a re-check of Free T4 and TSH six weeks post partum. Women will generally be asked to see their local doctor to discuss the results

NHMRC Level of evidence: III-3

GRADE C

9. A letter should be sent to the local doctor (with a copy to the patient) communicating the fact that levothyroxine had been used during pregnancy and the need to re-check Free T4 and TSH at 6 weeks postpartum

The letter should also provide a phone number for the local doctor to contact an experienced clinician at the hospital regarding any queries relating to the postpartum thyroid function results

NHMRC Level of evidence: Not applicable

GRADE Not applicable

*These Guidelines may be varied at the discretion of an experienced clinician.

NHMRC: National Health and Medical Research Council 


\section{University Library}

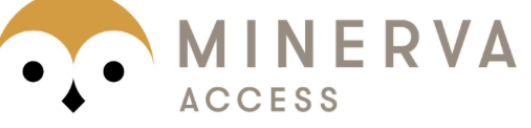

A gateway to Melbourne's research publications

Minerva Access is the Institutional Repository of The University of Melbourne

Author/s:

Hamblin, PS;Sheehan, PM;Allan, C;Houlihan, CA;Lu, ZX;Forehan, SP;Topliss, DJ;Gilfillan,

C;Krishnamurthy, B;Renouf, D;Sztal-Mazer, S;Varadarajan, S

Title:

Subclinical hypothyroidism during pregnancy: the Melbourne public hospitals consensus

Date:

2019-08-01

Citation:

Hamblin, P. S., Sheehan, P. M., Allan, C., Houlihan, C. A., Lu, Z. X., Forehan, S. P., Topliss, D. J., Gilfillan, C., Krishnamurthy, B., Renouf, D., Sztal-Mazer, S. \& Varadarajan, S. (2019). Subclinical hypothyroidism during pregnancy: the Melbourne public hospitals consensus. INTERNAL MEDICINE JOURNAL, 49 (8), pp.994-1000. https://doi.org/10.1111/imj.14210.

Persistent Link:

http://hdl.handle.net/11343/286230 